\title{
Effect of Manual Hyperinflation and Suctioning in Prevention of Ventilator- Associated Pneumonia: A Randomized Clinical Trial
}

Authors

\section{Sonal Shashikant Bhavane ${ }^{1}$, Milka Madhale 2* $^{\text {* }}$}

${ }^{1}$ Department of Medical and Surgical Nursing, KLE University's Institute of Nursing Sciences, Nehru

Nagar, Belgaum-590010, Karnataka, India

${ }^{2}$ Department of Medical and Surgical Nursing, KLE University's Institute of Nursing Sciences, Nehru

Nagar, Belgaum-590010, Karnataka, India

*Corresponding Author

Milka Madhale

Department of Medical and Surgical Nursing, KLE University's Institute of Nursing Sciences, Nehru Nagar, Belgaum-590010, Karnataka, India

\section{Abstract}

Background: Late-onset ventilator associated pneumonia is leading pulmonary infection in mechanically ventilated patients.

Objective: To assess the effect of manual hyperinflation and suction techniques in patients receiving mechanical ventilation to prevent the risk of ventilator-associated pneumonia.

Method: Mechanically ventilated and intubated patient $s(n=30)$ included in this single-blind randomized trial were randomized into control and study group (lottery method). Patients were assessed for baseline parameters and airway clearance before (Day 1; pretest scores) and after (Day 3 and 5; post test scores) the test. Manual hyperinflation (15 min) and suctioning (15 sec) was administered in study group $(n=15)$ whereas control group $(n=15)$ was given suctioning $(15 \mathrm{sec})$ as a routine nursing care, three times a day for 5 days. Data was analyzed by using SPSS 16; $P<0.05$ was statistically significant difference.

Results: Significant difference was observed in the airway clearance, on day 5 in the study group as compared to the control group $(P<0.001)$ ). Effect of combination therapy was also found to be significant $(P<0.05)$ between the groups.

Conclusion: Routine and supportive airway management care for ventilated patients to prevent ventilatorassociated pneumonia could be implemented with the help of the outcome of present study.

Keywords: Manual hyperinflation, Suctioning, Airway clearance.

\section{Introduction}

Ventilator-associated pneumonia (VAP) is the leading infectious pulmonary complication in mechanically ventilated patients, affecting approximately $8 \%-28 \%$ of patients in the intensive care units (ICUs) ${ }^{(1)}$. It usually develops within $48 \mathrm{~h}$ of intubation and mechanical ventilation, although the risk of VAP remains throughout the mechanical ventilation period ${ }^{(2)}$.

The point of time at which VAP develops has important implications in the etiology, treatment, and diagnosis of this disease. Early-onset VAP occurs as a consequence of microaspiration of bacteria and/or virus colonizing in theoropharynx 
whereas late-onset VAP occurs5 or more days after intubation and is caused by organisms such as Pseudomonas aeruginosa, Stenotrophomonas maltophilia, Acinetobacter species and methicillin-resistant Staphylococcus aureus ${ }^{(3)}$. These microorganisms, present in the pulmonary parenchyma, lead to the development of an inflammatory response by the host, which may become systematic or remain localized, depending upon the severity of the disease ${ }^{(4)}$.

Mechanical ventilator support is administered for patients with respiratory distress in the ICUs due to various underlying conditions such as organ failure, cardiovascular disease, multiple fractures, renal dysfunction, neurological disorders, organ transplantation, cancer, and requirement of postoperative care. However, implementation of mechanical ventilation causes several vital changes in the patient's airway such as introduction of microorganisms, obstruction of airway, atelectasis and gas resorption in the distal part of the obstructed passage. Large atelectasis may even promote the risk of development of lung injury. In addition, persistent of sputum in the bronchial airways may provide an ideal environment for colonization of microorganisms, which finally results in VAP. Thus, proper care of the airway is critical in preventing VAP as the virulence of microorganisms and prior host diseases are nonmodifiable factors during the treatment period by means of ventilation ${ }^{(5)}$.

Many investigators have attempted methods such as suctioning and manual hyperinflation $(\mathrm{MH})$ to pre-emptively remove these secretions with the goal of reducing microaspiration and the risk of $\mathrm{VAP}^{(6,7)}$. Suctioning of the endotracheal passage is broadly aimed at increasing the alveolar oxygenation, mobilizing pulmonary secretions, reducing ventilation perfusion mismatch, decreasing alveolar $\mathrm{CO}_{2}$ and improving static and dynamic lung compliance ${ }^{(7)}$. On the other hand, MH provides a larger tidal volume to patients than ventilator, mobilizes secretions, and improves lung volume along with the promotion of ventilation $^{(6)}$. As very few research have been done on the effect of combination therapy on mechanically ventilated patients, the following study has been performed to investigate the effect of combination chest physiotherapy involving suctioning and $\mathrm{MH}$ on mechanically ventilated patients to reduce the risk of VAP.

\section{Methods}

\section{Selection criteria}

The single-blind, randomized-control trial was conducted at the Markandeya ICU of KLE's Dr. Prabhakar Kore Hospital and Medical Research Center, Belgaum. The study evaluated 30 patients on mechanical ventilation who were aged between 25 and 56years. Patients requiring fraction of inspired oxygen $\left(\mathrm{FiO}_{2}\right)$ more than 0.8, having positive end expiratory pressure (PEEP) more than $10 \mathrm{~cm} \mathrm{H}_{2} \mathrm{O}$ or arterial oxygen saturation less than $80 \%$, and patients with unstable cardiovascular condition, were excluded from the study. Patients prescribed with head-up position for brain condition or having pulmonary condition were lung hyperinflation was contraindicated. Consent from the participants or their relatives were obtained before the commencement of the study and ethical clearance for the study was obtained from the Ethical Committee, KLE's Dr. Prabhakar Kore Hospital and Medical Research Center, Belgaum.

\section{Research design}

Patients were randomized into study and control groups by simple random sampling - lottery method considering the patient's age, gender, underlying disease, type of intubation, mode of ventilation, and $\mathrm{FiO}_{2}$. Control group $(\mathrm{n}=15)$ was provided routine nursing care with suctioning for $15 \mathrm{sec}$, whereas the study group $(\mathrm{n}=15)$ was administered manual hyperinflation for $15 \mathrm{~min}$ followed by suctioning for $15 \mathrm{sec}$. This procedure was followed three times a day for 5 days. The intervention procedures ( $\mathrm{MH}$ and suctioning) was performed for the study group on day 2 and 4 . 


\section{Assessment}

Pre- and post-treatment (day 3 and 5) assessment was conducted based on the observational checklist and modified clinical pulmonary infection scores (CPIS). Assessment was done to evaluate airway clearance, improvement in lung compliance, and extent of diagnosis of VAP in critical care setting. Observational checklist included preliminary assessment, nursing practices, Glasgow coma scale, vital signs, ventilator parameters, finding of the arterial blood gas analysis and auscultation, dynamic and static lung compliance, and secretion clearance (wet sputum collection). The positive and negative answers were indicated by ' 1 ' and ' 0 ', respectively.

Microbial evaluation was done and tracheal secretions, chest X-ray infiltrations, body temperature of the patients, leukocyte count, ratio of partial pressure to $\mathrm{FiO}_{2}$, and mean arterial pressure were measured using modified CPIS.A score of more than six indicated pneumonia in the CPIS scale.

\section{Intervention}

The patients in both the groups were intubated and mechanically ventilated on Maquet servo900 ventilator and kept on either volume control or synchronized intermittent mandatory ventilation and pressure support mode. The patients were exposed to routine medical, nursing care, laboratory and diagnostic investigations, as prescribed by physicians.

Routine nursing care for airway management included medical hand washing following aseptic techniques, adaptation of ventilator bundle care, head-end elevation to $30^{\circ}$, back care, and change of position. The processes of gowning and donning were strictly followed. This was followed by a specific treatment for control and treated groups, as described in previous section (section 2.2).

\section{Data analysis}

The data obtained in the study were analyzed by performing paired and unpaired t-test using SPSS
16.0 version. Paired t-test was used to compare the scores of airway clearance within the group, whereas unpaired t-test was used to compare the pretreatment and post-treatment assessment scores between control and study groups for airway clearance.

\section{Results}

\section{Baseline parameter of intubated patients on mechanical ventilation}

Data related to age, gender, type of intubation, mode of ventilation, and $\mathrm{FiO}_{2}$ were recorded. Majority of the patients in the control group were of 36-45 years of age whereas patients in the study group were found to be majorly in the age group of 25-35 years. Male predominance was observed among the patients in both the groups. Maximum patients were provided with emergency type of intubation and were on synchronized intermittent mandatory ventilation mode with pressure support (SIMV+PS), apart from being supported on $60 \% \mathrm{FiO}_{2}$ (Table 1).

\section{Assessment using observational checklist}

Improvement in airway clearance in the intubated and mechanically ventilated patients was observed upon comparison of the mean scores in control and study groups on day 3 and 5(Table 2). On the other hand, the assessment of airway clearance within the control group did not show significant improvement ( $p>0.05$; Table 3). However, significant $(p<0.01)$ improvement was observed after the assessment of airway clearance within the study group (Table 3).

\section{Assessment using modified CPIS scores}

Modified CPIS method revealed significant improvement in airway clearance in study group as compared to control group (Table 2). The comparison of pretest with post-test scores on day 5 of the control group suggested significant difference $(p<0.05)$ in the airway management (Table 4).The post-test scores between day 3 and 5 was also significant in the control group. Similar results were obtained upon comparison on pre and post test scores in the study group (Table 4). 
Comparison of the mean difference scores between the control and study group by unpaired t-test based for modified CPIS was not significant $(p=0.81)$. On the other hand, significant difference was obtained after comparison of posttest values on day $3(p=0.001)$ and $5(p<0.0001)$ between control and study groups (Table 2$)$.
Post-test assessment of combination therapy

Upon analysis of baseline parameters on sixth day for the presence of VAP in the control group, majority $(47 \%)$ of the patients were observed to be above 46 years of age, similar to the patients in the study group. Comparison of post-test with pretest assessment indicates effectiveness of the combination therapy in all the age groups.(Table 5)

Table 1: Frequency distribution of intubated and mechanically ventilated subjects among the study groups

\begin{tabular}{|c|c|c|c|c|}
\hline \multirow[t]{2}{*}{ Sl. No. } & \multicolumn{2}{|c|}{ Baseline parameters } & \multirow{2}{*}{$\begin{array}{c}\begin{array}{c}\text { Study group } \\
(\mathbf{n}=15)\end{array} \\
\mathbf{n}(\%) \\
\end{array}$} & \multirow{3}{*}{$\begin{array}{c}\begin{array}{c}\text { Control group } \\
(\mathbf{n}=15)\end{array} \\
\mathbf{n}(\%) \\
(12 \%)\end{array}$} \\
\hline & \multirow{5}{*}{ Age (years) } & & & \\
\hline \multirow[t]{4}{*}{1} & & $25-35$ & $5(33.3)$ & \\
\hline & & $36-45$ & $4(26.7)$ & $6(40)$ \\
\hline & & $46-55$ & $4(26.7)$ & $3(20)$ \\
\hline & & $>56$ & $2(13.3)$ & $4(26.7)$ \\
\hline \multirow[t]{2}{*}{2} & \multirow[t]{2}{*}{ Gender } & Male & $13(86.7)$ & $14(93.3)$ \\
\hline & & Female & $2(13.3)$ & $1(6.7)$ \\
\hline \multirow[t]{2}{*}{3} & \multirow[t]{2}{*}{ Type of intubation } & Elective & $7(46.7)$ & $4(26.7)$ \\
\hline & & Emergency & $8(53.3)$ & $11(73.3)$ \\
\hline \multirow[t]{2}{*}{5} & \multirow[t]{2}{*}{ Mode of ventilation } & Volume control & $2(13.3)$ & $2(13.3)$ \\
\hline & & SIMV + PS & $13(86.7)$ & $13(86.7)$ \\
\hline \multirow[t]{4}{*}{6} & \multirow{4}{*}{$\mathrm{FiO}_{2}(\%)$} & 40 & $3(20)$ & $2(13.3)$ \\
\hline & & 50 & $4(26.7)$ & $4(26.7)$ \\
\hline & & 60 & 7 (46.6) & $6(40)$ \\
\hline & & 70 & $1(6.7)$ & $3(20)$ \\
\hline
\end{tabular}

Table 2: Comparison of mean and standard deviation values of observational checklist and modified CPIS in both groups by unpaired t-test

\begin{tabular}{|c|c|c|c|c|c|c|c|}
\hline \multirow{2}{*}{$\begin{array}{l}\text { Days of } \\
\text { treatment }\end{array}$} & \multirow{2}{*}{ Category } & \multicolumn{3}{|c|}{ Observational checklist } & \multicolumn{3}{|c|}{ Modified CPIS scores } \\
\hline & & Mean & SD & $P$ value & Mean & SD & $P$ value \\
\hline \multirow[t]{2}{*}{ Day 1} & Control & 18 & 0.85 & \multirow[b]{2}{*}{0.72} & 7.7 & 0.7 & \multirow[b]{2}{*}{0.81} \\
\hline & Study & 18.1 & 0.7 & & 7.8 & 0.8 & \\
\hline \multirow[t]{2}{*}{ Day 3} & Control & 18.1 & 0.96 & \multirow{2}{*}{$<0.001$} & 7.7 & 0.7 & \multirow{2}{*}{0.001} \\
\hline & Study & 31.2 & 1.14 & & 6.8 & 0.5 & \\
\hline \multirow[t]{2}{*}{ day 5} & Control & 18.2 & 0.9 & \multirow{2}{*}{$<0.001$} & 6.9 & 0.9 & \multirow{2}{*}{$<0.0001$} \\
\hline & Study & 42 & 1.7 & & 5.3 & 0.9 & \\
\hline
\end{tabular}

Table 3: Comparison of airway clearance in control and study groups using paired t-test based on observational checklist scores.

\begin{tabular}{|c|c|c|c|c|}
\hline Score comparison & Days & Mean difference & SD & $P$ value \\
\hline \multicolumn{5}{|l|}{ Control group } \\
\hline \multirow{2}{*}{$\begin{array}{l}\begin{array}{l}\text { Pretest and post test } \\
\text { scores }\end{array} \\
\end{array}$} & Day 1 and 3 & 0.1 & 0.7 & 0.72 \\
\hline & Day 1 and 5 & 0.2 & 0.9 & 0.384 \\
\hline & Day 3 and 5 & 0.1 & 0.8 & 0.547 \\
\hline \multicolumn{5}{|l|}{ Study group } \\
\hline \multirow{2}{*}{$\begin{array}{l}\text { Pretest and post test } \\
\text { scores }\end{array}$} & Day 1 and 3 & 13.1 & 1.30 & $<0.00001$ \\
\hline & Day 1 and 5 & 23.9 & 1.75 & $<0.00001$ \\
\hline Post-test scores & Day 3 and 5 & 10.8 & 1.70 & $<0.00001$ \\
\hline
\end{tabular}


Table 4: Comparison of airway clearance in control and study groups using paired t-test based on Modified CPIS

\begin{tabular}{|c|c|c|c|c|}
\hline Score comparison & Days & Mean difference & SD & P values \\
\hline \multicolumn{5}{|l|}{ Control group } \\
\hline \multirow{2}{*}{$\begin{array}{l}\text { Pre-test and post test } \\
\text { scores }\end{array}$} & Day 1 and 3 & 0.0 & 0.5 & 1 \\
\hline & Day 1 and 5 & 0.8 & 1.2 & 0.022 \\
\hline Post-test scores & Day 3 and 5 & 0.8 & 1.2 & 0.022 \\
\hline \multicolumn{5}{|l|}{ Study group } \\
\hline \multirow{2}{*}{$\begin{array}{l}\text { Pre-test and post test } \\
\text { scores }\end{array}$} & Day 1 and 3 & 1.0 & 0.85 & $<0.001$ \\
\hline & Day 1 and 5 & 2.5 & 1.1 & $<0.00001$ \\
\hline Post-test scores & Day 3 and 5 & 1.53 & 1.1 & $<0.001$ \\
\hline
\end{tabular}

Table 5: Comparison of patients who acquired VAP in study and control groups on 6th day of intubation

\begin{tabular}{|c|c|c|c|c|}
\hline Sl. No. & \multicolumn{2}{|c|}{ Baseline parameters } & Study group $(n=15)$ & Control group $(n=15)$ \\
\hline \multirow{3}{*}{1} & \multirow{3}{*}{ Age (years) } & 3645 & $0(0)$ & $2(133)$ \\
\hline & & $46-55$ & $2(13,3)$ & $3(20)$ \\
\hline & & $>56$ & $1(6.6)$ & $4(26.6)$ \\
\hline \multirow[t]{2}{*}{2} & \multirow[t]{2}{*}{ Gender } & Male & $3(20)$ & $8(53.3)$ \\
\hline & & Female & $0(0)$ & $1(6.6)$ \\
\hline \multirow[t]{2}{*}{3} & \multirow{2}{*}{$\begin{array}{l}\text { Type of } \\
\text { intubation }\end{array}$} & Elective & $2(13.3)$ & $2(13.3)$ \\
\hline & & Emergency & $1(6.6)$ & 7 (46.6) \\
\hline \multirow[t]{2}{*}{4} & \multirow{2}{*}{$\begin{array}{c}\text { Mode of } \\
\text { ventilation }\end{array}$} & Volume control & $0(0)$ & $0(0)$ \\
\hline & & SIMV+PS & $3(20)$ & $9(60)$ \\
\hline \multirow[t]{4}{*}{5} & \multirow[t]{4}{*}{$\mathrm{FiO}_{2}(\%)$} & 40 & $0(0)$ & $2(13.3)$ \\
\hline & & 50 & $1(6.6)$ & $3(20)$ \\
\hline & & 60 & $2(13.3)$ & $3(20)$ \\
\hline & & 70 & $0(0)$ & $1(6.6)$ \\
\hline
\end{tabular}

\section{Discussion}

Evaluation of the effect of manual hyperinflation and suctioning was performed in the present study for the prevention of VAP. Manual hyperinflation and suctioning, termed as the combinational therapy, was evaluated using observational checklist scores and modified CPIS scores.

The present study demonstrated male predominance among the VAP patients, in accordance with a similar study by Choi and Jones in $2005^{(6)}$. Post-test assessment (on day 5) of control and study groups was found to be highly significant $(p<0.001)$ in the comparison to the pretest analysis that is, on day 1 indicating effective treatment of VAP patients with the help of combinational therapy. In addition, the airway clearance assessed in the study group with the help of both the assessment methods was also found to be significant, at the end of the study, indicating effective airway clearance with the help of combinational therapy.
The effective airway clearance in turn indicates improved lung compliance in VAP patients ${ }^{(8)}$. This improvement with the help of combinational therapy (manual hyperinflation and suctioning) has also been reported by similar studies ${ }^{(6,9)}$. Effective mobilization of pulmonary secretions into the central airway from the periphery airway followed by removal of secretions with the help of suctioning may have probably lead to the effective airway clearance with the help of combinational therapy ${ }^{(6)}$.

The assessment of the VAP patients at the end of the therapy (on day 6) further validated the improvement in health condition of the patients by the application of the combinational therapy. In addition, studies on application of combinational therapy on chest report reduction in rates of mortality, along with improvement of $\mathrm{VAP}^{(10,11)}$. Jesssica et al. ${ }^{(6)}$ also reported the various beneficial changes, which occur in respiratory mechanics upon administration of the combination therapy involving manual hyperinflation and 
suctioning, indicating the effectiveness of the therapy in the treatment of VAP patients.

\section{Conclusion}

From the present study, it could be concluded that application of combination therapy including manual hyperinflation followed by suctioning is highly effective in preventing the risk of VAP in intubated and mechanically ventilated patients. Therefore, this study outcome could be included as a routine and supportive airway management care for ventilated patients to prevent VAP.

\section{Conflict of Interest}

Authors declare that there is no Conflict of Interest.

\section{References}

1. Goel V, Hogade SA, Karadesai S. Ventilator associated pneumonia in a medical intensive care unit: Microbial aetiology, susceptibility patterns of isolated microorganisms and outcome. Indian J Anaesth 2012:56: 558562.doi:10.4103/0019-5049.104575

2. Koenig SM, Truwit JD. Ventilatorassociated pneumonia: diagnosis, treatment, and prevention. Clin Microbiol Rev 2006:19:637657.doi:10.1128/CMR.00051-05

3. Chastre J, Fagon JY. Ventilator-associated pneumonia. Am J Respir Crit Care Med 2002, 165, 867-903. doi:10.1164/ajrccm.165.7.2105078

4. Rea-Neto A, Youssef NC, Tuche F, Brunkhorst F, Ranieri VM, Reinhart K, et al.Diagnosis of ventilator-associated pneumonia: a systematic review of the literature. Crit Care 2008:12: R56. doi:10.1186/cc6877
5. Diaz E, Rodriguez AH, Rello J. Ventilatorassociated pneumonia: issues related to the artificial airway. RespirCare 2005:50:900906; discussion 6-9.

6. Choi JS, Jones AY.Effects of manual hyperinflation and suctioning in respiratory mechanics in mechanically ventilated patients with ventilatorassociated pneumonia. Aust J Physiother 2005:51:25-30.

7. Brazier D. Effects of Manual Lung Hyperinflation Using Rebreathing Bags on Cardiorespiratory Parameters in Intubated Adults. Phys Ther Rev 2003:8:135-141. doi:10.1179/108331903225002461

8. Clini E, Ambrosino N. Early physiotherapy in the respiratory intensive care unit. Respir Med 2005: 99: 10961104. doi:10.1016/j.rmed.2005.02.024

9. El-Rhman EHA, Mohamed A, Shendy, Ahmed H. Effects of Manual Hyperinflation and Suction on Lung Compliance in Ventilated Patients in Different Positions. World Journal of Medical Sciences 2015:12:297-302. doi:10.5829/idosi.wjms.2015.12.3.962

10. Pattanshetty RB, Gaude GS.Effect of multimodality chest physiotherapy in prevention of ventilator-associated pneumonia: A randomized clinical trial. Indian J Crit Care Med 2010:14:70-76. doi:10.4103/0972-5229.68218

11. Ntoumenopoulos G, Presneill JJ, McElholum M, Cade JF. Chest physiotherapy for the prevention of ventilator-associated pneumonia. Intensive Care Med 2002:28:850-856. doi:10.1007/s00134-002-1342-2. 